\title{
Formação do Professor de Matemática Mediada pelo Coordenador Pedagógico
}

\author{
Caio Augusto Xavier Fernandes \\ Armando Traldi Jr
}

\begin{abstract}
Resumo: Neste artigo, será apresentado o estudo que teve como objetivo compreender possibilidades e desafios ao investigar uma formação em serviço de um professor de matemática, mediada pelo coordenador pedagógico. Foi realizada uma pesquisa qualitativa do tipo ação-interpretativa, pois o estudo foi desenvolvido na escola onde o pesquisador exerce a função de coordenador pedagógico. Os dados analisados foram obtidos a partir de observações de aulas e do Feedback realizado entre o professor de matemática e o coordenador pedagógico. Os resultados encontrados revelam desafios referentes ao tempo a ser dedicado pelo coordenador pedagógico na elaboração e preparação da pauta formativa e a falta de uma formação específica do Professor Coordenador $(\mathrm{PC})$ para desenvolver formação de professores. Em relação às possibilidades, destaca-se a possibilidade de problematizar a prática real em sala de aula durante o Feedback formativo.
\end{abstract}

Palavras-chave: Formação do professor de matemática. Observação sala de aula. Feedback formativo.

Caio Augusto Xavier Fernandes Mestre em Ensino de Ciências e Matemática pelo Instituto Federal de Educação, Ciência e Tecnologia de São Paulo, Campus São Paulo. Professorcoordenador da Rede Estadual de São Paulo, São Paulo, SP, Brasil. https://orcid.org/0000-0001-

9983-3050

$\triangle$ caioxavier82@hotmail.com

Armando Traldi Jr Doutor em Educação em Matemática pela Pontifícia Universidade Católica (PUC-SP). Professor do Instituto Federal de Educação, Ciência e Tecnologia de São Paulo, Campus São Paulo, São Paulo, SP, Brasil. (iD) https://orcid.org/0000-0001-8337-3977 $\square$ traldij@gmail.com

Recebido em 18/01/2021 Aceito em 09/02/2021 Publicado em 19/02/2021

\section{Mathematics Teacher Training Mediated by Pedagogical Coordinator}

Abstract: In this article, the study that aims to understand possibilities and challenges when investigating in-service training for a mathematics teacher mediated by the pedagogical coordinator will be presented. A qualitative actioninterpretive research was carried out, as the study was developed at the school where the researcher exercises the role of pedagogical coordinator. The analyzed data were obtained from observations of classes and from the Feedback made between the mathematics teacher and the pedagogical coordinator. The results found reveal challenges regarding the time to be devoted by the pedagogical coordinator in the preparation and preparation of the formative agenda and the lack of specific training for the coordinating teacher to develop teacher training. Regarding the possibilities, the possibility of problematizing real classroom practice during formative Feedback is highlighted.

Keywords: Mathematics teacher training. Classroom observation. Formative Feedback.

\section{Formación Docente de Matemáticas Mediada por Coordinadora Pedagógica}

\begin{abstract}
Resumen: En este artículo se presentará el estudio que tiene como objetivo comprender las posibilidades y desafíos a la hora de investigar la formación en servicio de un docente de matemáticas mediado por el coordinador pedagógico. Se realizó una investigación cualitativa acción-interpretativa, ya que el estudio se desarrolló en la escuela donde el investigador ejerce el rol de coordinador pedagógico. Los datos analizados se obtuvieron de observaciones de clases y de la retroalimentación realizada entre el profesor de matemáticas y el coordinador pedagógico. Los resultados encontrados revelan desafíos en cuanto al tiempo que debe dedicar el coordinador pedagógico en la elaboración y elaboración de la agenda formativa y la falta de formación específica del maestro coordinador para desarrollar la formación docente. En cuanto
\end{abstract}


a las posibilidades, se destaca la posibilidad de problematizar la práctica real del aula durante la retroalimentación formativa.

Palabras clave: Formación de profesores de matemáticas. Observación en el aula. Retroalimentación formativa.

\title{
1 Introdução
}

A realização da formação do professor no seu ambiente de trabalho é uma estratégia promissora para o enfrentamento de desafios que emergem da rotina escolar. Candau (2003) afirma que:

\begin{abstract}
Na experiência dos professores, o dia a dia na escola é um locus de formação. Nesse cotidiano, ele aprende, desaprende, reestrutura 0 aprendido, faz descobertas e, portanto, é nesse locus que muitas vezes ele vai aprimorando a sua formação. Nesse sentido, considerar a escola como locus de formação continuada passa a ser uma afirmação fundamental na busca de superar o modelo clássico de formação continuada e construir uma nova perspectiva na área de formação continuada de professores. Mas este objetivo não se alcança de uma maneira espontânea, não é o simples fato de estar na escola e de desenvolver uma prática escolar concreta que garante a presença das condições mobilizadoras de um processo formativo. Uma prática repetitiva, uma prática mecânica não favorece esse processo (p. 73).
\end{abstract}

Nóvoa (2002), porém, afirma que para ocorrer a formação em serviço é necessário que sejam provocadas situações de reflexões sobre as ações da prática escolar indo além da experimentação, provocando inovações pelo ensaio de novos modos de trabalho pedagógico.

É no sentido de criar um ambiente propicio para reflexões que a presença do coordenador pedagógico (CP) pode ser uma peça central para que ocorra a formação em serviço, pois ele está na escola e é conhecedor da infraestrutura e da comunidade escolar, portanto, pode firmar uma boa parceria de formação com os professores, de acordo com Gouveia e Placco (2013).

Almeida e Placco $(2009$, p. 3) explicitam a função do CP como formador:

[...] compete-lhe oferecer condições ao professor para que se aprofunde em sua área especifica e trabalhe bem com ela; como transformador, cabe-lhe o compromisso com o questionamento, ou seja, ajudar o professor a ser reflexivo e crítico com a sua prática.

A relação entre CP e professor em momentos de formação tem sido objeto de estudo de diferentes pesquisas desenvolvidas no Brasil na busca de compreender como ocorrem esses momentos. Estudos como o de Souza (2017), o de Sampaio (2018), e o de Oliveira (2018) investigaram a função do coordenador pedagógico nas escolas, considerando aspectos das suas funções de trabalho e ações relacionadas à formação de professores.

Ao analisar esses estudos é possivvel afirmar que as formações elaboradas pelos $\mathrm{CP}$, geralmente, abordam temáticas internas à escola, dando um maior significado e sentido às formações, pois os participantes da formação enfrentam desafios parecidos e já conhecem a infraestrutura da escola. Outro aspecto relevante é a possibilidade de os encontros acontecerem, 
pois já está previsto na grade horária desses profissionais um espaço de tempo para os encontros entre CP e professores.

Os desafios listados nesses estudos, por outro lado, estão relacionados com a falta de tempo para o PC preparar essas formações, visto que esse profissional tem uma série de outras atribuições: atendimento aos pais, orientação aos alunos, suporte ao professor, relação direta com equipe gestora, preparo de reuniões; além desse, o fato de o coordenador pedagógico não ter, em sua graduação e rotina de trabalho, espaço e tempo reservados para sua própria formação como formador de professor.

Apesar dos desafios atribuídos ao CP para exercer a função de formador, é possível afirmar que esse profissional tem um grande potencial para ser um formador de professor, contribuindo com a qualidade da educação, mas, para que isso se concretize, é necessário o desenvolvimento de estudos que busquem ampliar os conhecimentos referentes à parceria entre $\mathrm{CP}$ e professores, fazendo com que dessa parceria surjam formações qualificadas à melhoria do ensino.

Outro aspecto observado nos estudos analisados é que todos têm como objeto de estudo a ação do CP, analisando sua rotina de trabalho e as estratégias que utilizam nas formações.

O trabalho do professor-coordenador é fundamentalmente um trabalho de formação continuada em serviço. Ao subsidiar e organizar a reflexão dos professores sobre as razões que justificam suas opções pedagógicas e sobre as dificuldades que encontram para desenvolver seu trabalho, o professor coordenador está favorecendo a tomada de consciência dos professores sobre suas ações e o conhecimento sobre o contexto escolar em que atuam (PIMENTA, 2002, p. 9).

Conforme revela Pimenta (2002), o professor coordenador é um profissional que atua na escola com o potencial de um formador, portanto, justificam-se pesquisas que busquem compreender as potencialidades das parcerias CP e professor no ambiente de formação.

Sendo assim, o estudo apresentado neste artigo teve como objetivo compreender possibilidades e desafios de realizar uma formação em serviço entre CP e um professor de matemática, concebida a partir das observações da sala de aula.

\section{Pressuposto teórico: formação em serviço}

São várias as terminologias utilizadas no decorrer dos anos para a formação continuada. A autora Marin (1995) traz: reciclagem, treinamento, aperfeiçoamento, capacitação, educação permanente, formação continuada e educação continuada.

O objetivo deste trabalho é olhar para a formação em serviço, com foco nas características desse processo e a contribuição. Neste trabalho, será exposto um caso de formação continuada em serviço, promovida pelo professor coordenador a um professor de matemática que atua na 
EJA. A formação, em si, ocorreu de forma individual após observações feitas da aula do referido professor.

De acordo com Almeida "[...] é preciso que haja espaços para que os professores se encontrem, troquem suas vivências, reelaborem suas experiências e tenham retaguarda para implantar seus planos" (ALMEIDA, 2006, p. 85).

Almeida (2006) descreve uma situação de formação continuada de professores concomitante à atuação profissional. Esse tipo de formação é denominado formação continuada em serviço. É a formação que emerge das necessidades dos professores, de situações em que aparecem em seu cotidiano, muitas vezes, mediada por um professor coordenador.

Placco (2002) menciona que o processo de formação em serviço precisa: (i) estar atrelado ao projeto político pedagógico; (ii) ser planejado de forma coletiva; (iii) ter espaços e tempos para que ocorra a participação de todos, como a reflexão da docência e experiência profissional; (iv) que o compromisso seja não apenas dos gestores, mas dos educadores também.

Corroborando a dimensão de formação continuada em serviço, proposta por Placco (2002), pode-se constatar que ela vai além de uma simples melhora na prática pedagógica do professor. Ela busca atender as demandas e as necessidades do meio em que aquele professor atua, de forma que colabore com o processo pedagógico da escola.

Nessa perspectiva, Freire (2001, p. 72) aponta que:

A melhora da qualidade da educação implica a formação permanente dos educadores. E a formação permanente se funda na prática de analisar a prática. É pensando sua prática, naturalmente com a presença de pessoal altamente qualificado, que é possível perceber embutida na prática uma teoria ainda não percebida ainda, pouco percebida ou já percebida, mas pouco assumida.

De forma que se garanta a melhora da qualidade da educação apontada por Freire (2001), Nóvoa (2002), em sua obra intitulada: "Formação de professores e trabalho pedagógico", apresenta cinco teses, que são:

Primeira tese: A formação contínua de professores deve alimentar-se de perspectivas inovadoras, que não utilizem preferencialmente "formações formais", mas que procurem investir, do ponto de vista educativo, nas situações escolares.

Segunda tese: A formação contínua deve valorizar as atividades de (auto) formação participada e de formação mútua, estimulando a emergência de uma nova cultura profissional no seio do professorado.

Terceira tese: A formação continuada deve alicerçar-se numa "reflexão na prática e sobre a prática", através de dinâmicas de investigação - ação e de investigação - formação, valorizando os saberes de que os professores são portadores. 
Quarta tese: É necessário incentivar a participação de todos os professores na concepção, realização e avaliação dos programas de formação contínua e consolidar redes de colaboração e espaços de parceria que viabilizem uma efetiva cooperação institucional.

Quinta tese: A formação contínua deve capitalizar as experiências inovadoras e as redes de trabalho que já existem no sistema escolar, investindo-as do ponto de vista de sua transformação qualitativa, em vez de instaurar novos dispositivos de controle e de enquadramento.

Em síntese, Nóvoa (2002) afirma que as situações escolares devem ser o eixo organizador das formações, portanto, o ambiente escolar torna-se o mais indicado para essas construções. Deve-se valorizar a auto formação e as reflexões da prática do docente. Que todos os professores participem e valorizem seus conhecimentos e práticas já consolidadas.

Nesta pesquisa, iremos abordar as situações escolares do ambiente em que o professor participante atua, como também incentivar, escutar e dialogar com o professor. A formação ocorreu a partir da observação da prática do professor e dos diálogos sobre essa prática.

\section{Cenário da Pesquisa}

A presente pesquisa consiste em uma abordagem qualitativa, que, segundo Silveira (2009, p. 31): "[...] não se preocupa com representatividade numérica, mas, sim, com o aprofundamento da compreensão de um grupo social, de uma organização, etc.". O estudo desenvolvido teve como objetivo compreender possibilidades e desafios de realizar uma formação em serviço mediada pelo CP para um professor de matemática, concebida a partir das observações da sala de aula e guiadas pela ficha de observação na perspectiva do PC.

O professor coordenador, neste estudo, é o próprio pesquisador, que vai ao encontro do que Silva (2019) afirma: "Na pesquisa qualitativa, o cientista é ao mesmo tempo o sujeito e o objeto de suas pesquisas".

Quanto aos procedimentos do trabalho, anunciamos que se trata de uma pesquisa-ação. Segundo Fonseca (2002, p. 34):

\footnotetext{
A pesquisa-ação pressupõe uma participação planejada do pesquisador na situação problemática a ser investigada. O processo de pesquisa recorre a uma metodologia sistemática, no sentido de transformar as realidades observadas, a partir da sua compreensão, conhecimento e compromisso para a ação dos elementos envolvidos na pesquisa.
}

Essa definição se encaixa no contexto da pesquisa, pois o pesquisador planejou observar a aula de um determinado professor e, munido de observações e anotações, realizar um diálogo com esse docente. 
A pesquisa ocorreu em uma escola pública estadual, situada na cidade de Atibaia/SP, localizada na região central, onde, durante o dia, funciona o Programa Ensino Integral (PEI), com quatorze turmas, sendo nove turmas do Ensino Fundamental Anos Finais e cinco do Ensino Médio. Já no período noturno, a escola funciona com dez salas, sendo uma turma da $2^{\mathrm{a}}$ série do Ensino Médio Regular e nove turmas da Educação de Jovens e Adultos do Ensino Médio.

Com relação aos materiais didáticos disponíveis, a escola tem em seu acervo: livros didáticos de todos os componentes curriculares; material "São Paulo faz escola", distribuído pela Secretaria da Educação (SEDUC) e o material "EJA Mundo do Trabalho", um material específico e destinado ao público da EJA.

A observação da aula do professor foi em uma turma de $3^{\circ}$ Termo, composta por vinte e nove alunos. Nos dias em questão, estavam presentes em média vinte alunos. 0 critério para que a observação fosse realizada nessa turma foi pela sugestão do professor, que apontou a determinada turma como a mais participativa e por estar com o conteúdo em dia. Acreditamos que essas características poderiam colaborar com a pesquisa e as observações a serem feitas.

O professor coordenador, participante dessa pesquisa, atua nessa função desde outubro de 2017. Sua formação inicial é em Licenciatura em Matemática pelo Instituto Federal de Educação, Ciência e Tecnologia de São Paulo (IFSP), campus Bragança Paulista. Também é licenciado em Pedagogia. Atua na rede estadual desde agosto de 2012. A experiência profissional ocorreu no Ensino Fundamental Anos Finais e Ensino Médio, e na Educação de Jovens e Adultos.

O outro participante da pesquisa foi o professor que é um profissional formado em Licenciatura em Matemática, desde 2013. Atua há oito anos no magistério público e privado, tendo iniciado sua carreira no setor privado. Este é o terceiro ano atuando na escola cenário dessa pesquisa. Atualmente, ele trabalha como contratado na rede pública estadual e na rede privada. Com relação à experiência com a modalidade EJA, este é o quarto ano em que ele atua com esse público. A escolha desse profissional se deu por ser da mesma área de formação que o PC; pela carga horária que possui; por estar na escola todas as noites e pela experiência profissional com a Educação de Jovens e Adultos.

\section{Momentos das observações em sala de aula}

Foram observadas quatro aulas de quarenta e cinco minutos, e, para este artigo, foram selecionados alguns trechos dessas observações. As unidades utilizadas para observação foram escolhidas a partir do que é recomendado a ser observado na ficha de observação proposta pela Secretaria da Educação do Estado de São Paulo. A seguir, serão apresentadas algumas dessas unidades de observação. 


\subsection{0 professor recolhe e avalia evidências do progresso dos alunos para melhorar o ensino aprendizagem}

Nesta unidade de análise, foram observadas situações que possibilitaram a interação entre 0 docente e os estudantes, na expectativa do docente ter elementos para analisar 0 progresso de aprendizagem.

A seguir, é apresentado um trecho da fala e ações do professor, que evidenciam esta unidade de análise:

Professor: Alguém ficou com dúvida? Tem alguma pergunta? Alguma coisa?

(Os estudantes não se manifestam, então o professor pede para os alunos que já terminaram trazer o caderno para ele verificar).

Professor: Vamos lá pessoal, vamos começar com a correção para a gente dá continuidade. Sei que todo mundo já fez lá (se referindo a aula anterior), eu já observei de alguns. Vamos fazer rapidinho aqui, dá para corrigir mais rápido para adiantar, tá? [Observação da aula do dia 22/10/2019]

Nos trechos acima, podemos observar os momentos em que o professor realiza questionamentos aos alunos a fim de verificar se há dúvidas ou perguntas com relação ao conteúdo. Também pode-se perceber as situações em que o professor faz a devolutiva dos exercícios de forma individual, na qual os alunos vão até a sua mesa e ele corrige, questiona e fornece um parecer sobre as atividades apresentadas. E por fim, temos o momento da correção coletiva, do qual os alunos que não levaram o caderno para o professor têm a oportunidade de ter uma devolutiva, assim como acompanhar a resolução dos exercícios.

Apesar desse item não ter sido trabalhado na formação especificamente, é um tema importante de ser aludido durante as formações, pois este item aborda uma prática docente que auxilia no processo de ensino aprendizagem dos alunos.

\subsection{Os alunos estão envolvidos em conversas com o professor e colegas, sobre conceitos abordados na aula}

Nesta unidade de análise, foram analisadas e observadas situações em que tenham ocorrido diálogos entre os estudantes e entre estudantes e professor, relacionados à aula.

Trechos das falas e ações dos alunos envolvendo sua participação e interação que estejam relacionados com a aula.

Alunos começam a discutir a definição de número primo e questionam: Professor número primo é aquele que divide por ele mesmo e por um, né?

Professor: Só. 
(Dois alunos ao fundo da sala, começam a verificar quem são os números primos entre 1 a 50. Vão dizendo cada número verificando e contando na mão para anotar).

Aluno: Professor 7 é número primo é?

Professor: "Pega" o número 7 e divide por ele e por 1, o resultado tem que dá número inteiro.

Aluno: Da 7 e 1.

Professor: 07 dá para dividir por outro número?

Aluno: Não.

Professor: Então é número primo. [Observação da aula do dia 21/10/2019]

No trecho acima, podemos perceber diálogos e interações dos alunos entre si, e dos alunos com o professor. Todos estes diálogos estão relacionados com o conteúdo da aula, neste caso, sobre definição de números primos, que era um dos itens de um exercício.

É relevante observar os diálogos e interações que ocorrem durante as aulas, pois são estes diálogos, perguntas, colocações que demonstram o entrosamento dos alunos com a aula, se estão participando ativamente e se há interesse no que está sendo exposto pelo professor. É importante, porém, destacar que a questão proposta pelo professor "O 7 dá para dividir por outro número?" pode levar a uma conclusão equivocada do conceito por parte dos estudantes.

\title{
4.3 São estabelecidas ligações entre conceitos abordados e outros temas (contextualização)
}

Nesta unidade de análise, foram observadas situações em que o professor traz algo extra para a aula ou, até mesmo, conteúdos anteriores para fazer ligações. Exemplo de um trecho observado que o professor menciona um projeto desenvolvido no ano anterior:

\begin{abstract}
Aluna: Professor eu tenho uma dúvida. De onde o senhor tirou esse 5000 ? 60 vezes 5000 ? Professor: Ó tem a setinha aqui, 360 vezes $x, 360 x, 50$ vezes 100, 5000. No semestre passado quando a gente fez a feira científica, que a gente fez as exposições, vocês fizeram os gráficos, se a gente fosse fazer gráfico de setores, a gente teria trabalhado para fazer esses valores para compensar o outro, lembra que tantos porcentos valia cada coluna, cada tabela, você conseguia montar desse jeito também aqui ó, gráfico de setor, aí você pegava lá quantos por cento tinha $60 \%$ de crime, de homofobia. Se a gente fosse fazer desse jeito a gente ia pegar o 60\%, achar quantos graus tem e marcar certinho quantos graus tem e também daria pra fazer desse jeito. Que é de setor ou de pizza. Você viu galera isso é fácil, daria pra gente fazer, sei lá, na nossa feira. [Observação da aula do dia 23/10/2019]
\end{abstract}

No trecho anterior, o professor comenta sobre porcentagem, sobre proporcionalidade e relaciona com o conteúdo que os alunos trabalharam em forma de projeto "Feira Cultural". Neste evento, os alunos tinham um tema central e a partir deste realizavam pesquisas e apresentavam 
em forma de seminários. Em relação às aulas de matemática, os alunos elaboraram gráficos com diversas informações sobre a temática trabalhada. Assim sendo, o professor elucidou que se, por acaso, tivesse feito gráfico de setores, seria utilizada a porcentagem para a construção deste tipo de gráfico, em sala de aula.

\subsection{0 professor utiliza recursos eletrônicos para apoiar a aprendizagem}

Nesta unidade de análise, foram observadas situações em que poderiam ser utilizadas algumas dessas ferramentas: mapa, globo, tubo de ensaio, microscópio, calculadora, computador.

A seguir, apresentaremos um trecho de fala e de ação, na qual o professor incentiva e faz uso da ferramenta calculadora, como recurso pedagógico.

Professor: Lembrem que para a gente encontrar a porcentagem, existem maneiras mais complicadas e outras que são mais simples. Podemos calcular mentalmente ou quem souber e tiver, pode usar a calculadora. [Observação da aula do dia 21/10/2019]

No trecho, pode-se verificar o momento em que o professor sugere o uso da calculadora, mas comenta "... quem souber...", se a hipótese do professor é de que existe estudante que não sabe, poderia ter aproveitado o momento para ensinar.

\subsection{Momento da formação}

Após as observações em sala de aula, foi realizado o Feedback da formação em serviço em um único encontro. Este encontro ocorreu durante o horário reservado na carga horária do professor e do PC para a formação individual.

Optou-se por realizar a formação usando a estratégia do diálogo, propondo questões e mostrando trechos observados para que os itens da pauta emergissem da própria conversa, sem seguir uma sequência pré-determinada. Os assuntos previstos na pauta: i. Especificidades da Educação de Jovens e Adultos; ii. Conteúdos e Habilidades abordados em sala de aula; iii. Avaliação da aprendizagem e iv. Uso da calculadora em sala de aula.

O PC iniciou a conversa com o professor explicando que o Feedback seria pautado nas quatro aulas observadas na turma de $3^{\circ}$ termo da EJA do Ensino Médio. Comentou que foi possível observar que o professor tem um bom relacionamento com os estudantes; realiza intervenções quando se faz necessário e utiliza o material "EJA Mundo do Trabalho", que é uma recomendação 
da SEDUC. O professor comentou que estas características se dão pelo fato de lecionar para a mesma turma desde o semestre anterior, portanto, já conhece os alunos há algum tempo.

0 primeiro questionamento que o PC fez foi com relação à quantidade de exercícios propostos pelo docente durante as aulas e o questionou se ele considerou em número suficiente. $O$ professor relata que poderia ter passado mais, por ser uma sala que tem bom rendimento no geral. Alguns alunos, no entanto, não iriam acompanhar, por terem mais dificuldades.

O PC prossegue perguntando se além dos temas explorados durante as aulas sobre probabilidade, o professor poderia ter abordados outros temas.

PC: E você acha que poderiam ter outros conteúdos abordados, outras partes da probabilidade, que não foram, que o livro não trouxe e poderia ter sido ensinado para os estudantes?

Professor: Poderia. Mas, eu não alcançaria o total da sala. E ficaria um pessoal lá, que iria ficar um pouco para trás, que não conseguiria entender! Poucos, em torno de $10 \%$ no máximo!

PC: Certo! Porque tem outros tipos de probabilidade e conteúdo, como: probabilidade com evento repetido, eventos independentes, multiplicação de probabilidades, união de dois eventos que não foram abordados. Então, você acha que...

Professor: Então, até porque a apostila ela não aborda, é...essa...essa parte. Fica mais restrita.

PC: Tá! E se nós tivéssemos um material complementar? Você acha que daria conta?

Professor: Sim! . [Feedback formativo realizado nov/2019]

E o docente, mais uma vez, justifica que sim, mas não atingiria todos os estudantes da sala, somente uma minoria conseguiria acompanhar, além do material utilizado não abordar tais conteúdos. $O$ docente, no entanto, afirma que se adotasse um material complementar ao do "EJA Mundo do Trabalho", poderia ter tratado de forma diferente o conteúdo estudado.

Percebe-se que é recorrente o professor falar sobre a dificuldade dos alunos não observando as potencialidades de aprendizagem. Durante as aulas observadas, foi percebido pelo PC que muitos estudantes apresentavam conhecimentos prévios do conteúdo quando questionado pelo professor, e que havia estudantes interessados em aprender mais sobre 0 assunto, que eram os que demonstravam mais facilidade em resolver os exercícios propostos.

Dando prosseguimento a formação, o PC conversou com o professor sobre os conteúdos e habilidade abordada em sala de aula:

PC: Agora, falando em habilidade, eu tenho uma habilidade no currículo que é a seguinte: "Saber resolver problemas que envolvam o cálculo de probabilidades de eventos simples repetidos, como os que conduzem ao binômio de Newton". Essa habilidade não aparece nas suas aulas.

Professor: Não, não aparece!

$P C$ : Você considera que seria possivel trabalhar essa habilidade com as turmas da EJA?

Professor: Hum... não.

PC: Não? 
Professor: Não... eu creio que não.

$P C$ : E em uma turma do ensino regular? Seria possível?

Professor: Sim! Com mais tempo de trabalho, conseguindo abordar mais exercícios e tendo um livro com mais atividades, acredito que sim.

$P C$ : Então, no ensino regular você acha que é possivel trabalhar?

Professor: Sim!

$P C$ : E na EJA, por que você acha que não dá para trabalhar?

Professor: Tempo curto, nosso tempo de aula, duração semestral é mais curto. Ah... os alunos têm um pouco de defasagem, não a maioria, mas uma parcela bem significativa, em termos de: interpretação de texto, leitura para eles nesse contexto seria um pouco mais trabalhoso. Daria certo, se a gente tivesse um pouco mais de tempo.

PC: Certo.

Professor: Mas, eu acho que pela falta de tempo, por exatamente ser muito corrido, a gente não consegue abordar todo o conteúdo.

PC: Então, alguns alunos daquela sala em questão. Se trabalhasse essa habilidade, alguns alunos iriam conseguir?

Professor: Sim!

PC: Outros não?

Professor: Não, não conseguiria!

PC: Mas se houvesse um tempo maior, você conseguiria atingir também esses alunos também com aprendizagem?

Professor: Sim. Porque a gente conseguiria mostrar como funciona, passar na prática, passar atividades, consigo passar mais atividades em lousa e daria para atingir eles sim. [Feedback formativo realizado nov/2019]

Com relação à habilidade prevista no currículo para o Ensino Médio, o docente relata que, pelo fato das turmas da EJA serem semestrais, a carga horária desta modalidade ser menor que das turmas regulares, dificulta a abordagem de algumas habilidades, além da defasagem presente nas turmas da Educação de Jovens e Adultos.

Durante a formação, o PC não fez os contrapontos necessários sobre o equívoco mostrado pelo professor em relação ao perfil dos estudantes da EJA, pois além dessa modalidade não ser uma forma simplesmente aligeirada do estudo, propondo um resumo do ensino regular, também é importante que os estudantes matriculados nessa modalidade, geralmente, já tenham vivência profissional e social que possibilite abordagens de formas diferentes dos conteúdos.

O próximo assunto abordado foi sobre avaliação:

PC: Como que você avalia os alunos durante as aulas?

Professor: É... no final depois dos exercícios, eu peguei alguns exercícios referente a apostila e fiz algumas alterações e pedi como atividades.

PC: Mas isso foi depois de algumas aulas que eu assisti?

Professor: Sim, depois de umas três aulas.

PC: Mas naquelas quatro aulas você fez alguma avaliação assim deles?

Professor: Diária...

PC: Diária, avaliação contínua, formativa...

Professor: Individualmente. Ou coletiva?

PC: Você usou algum critério para avaliar eles? 
Professor: Sim. Deixando no decorrer das aulas um tempo para eles raciocinarem, tentar usar o raciocínio lógico. Que também dava em termos de probabilidade. Deixava-os fazerem as contas sozinhos, pois dava para resolver até por regra de três, por aproximações... eu os deixei mais livres. Por autonomia para eles tentarem fazer a conta e eu só acompanhando e orientando. Através disso, eu percebi que houve um avanço para as próximas atividades que na hora que chegou na parte mesmo de porcentagem, eles estavam mais livres para fazer a atividade.

PC: Certo. Percebi que durante as aulas você corrige as atividades realizadas no caderno. Professor: Uhum.

PC: Quando eles vão até a sua mesa. Você faz um controle de quem apresenta a atividade? Um controle sistemático de quem entrega e quem não entrega?

Professor: Faço. Faço isso no diário.

$P C$ : Então quando o aluno não leva o caderno para você é feita uma anotação no diário?

Professor: Faço uma anotação no diário. Ponho lá uma observação para quem entregou e para quem não entregou. Quem fez, quem fez todos corretamente. Eu corrijo os exercícios, nunca ponho errado no caderno. Quando ele erra a atividade. Não ponho literalmente 0 " $x$ " lá, dizendo que ele errou. Eu sempre ponho certo nas que estão corretas e nas erradas eu sempre peço para eles refazerem.

$P C$ : Deixa em aberto, para uma nova tentativa.

Professor: Exatamente. Refaça esse exercício porque alguma coisa de valor deu errado. Alguma conta... algo ele errou. Aí eles percebem que uma vírgula, alguma coisa não tá certa. Ai sim, eu corrijo novamente e dou o certo e o visto geral.

$P C$ : Certo. Observei que teve aluno durante a aula que não levou o caderno.

Professor: Sim.

PC: E que não resolveu. Queria saber qual era o seu controle de avaliação, vamos dizer assim, se todos estavam intelectualmente envolvidos na aula.

Professor: É esses alunos que realmente não trazem o caderno. São que efetivamente, por algum motivo não fez. Ou porque realmente não acompanhou ou é a sequência de falta que fez perder a atividade naquele dia. Ele acaba perdendo a base anterior, perdeu alguma explicação. Ou realmente não sabe, não quer fazer e esses são os que acabam deixando a sala um pouquinho desnivelada, não sei se posso falar assim.

PC: Certo.

Professor: Que é que dá o atraso em relação a continuidade da matéria.

PC: Sim. Mas tem alguns alunos que ficam esperando a correção para poder copiar, né?! Professor: Exatamente.

PC: A maioria, eu senti que durante o tempo para a realização dos exercícios vai até a sua mesa.

Professor: Procura.

PC: Procura para poder tirar a dúvida, dúvidas pontuais mesmo. E outros assim, ficam mais...

Professor: Sim. Esses alunos que realmente só esperam a correção para copiar, acabam ficando sem o tal visto, a anotação para critérios de avaliação, o rendimento cai.

$P C$ : Então nessa questão você tem um controle de quem faz e quem não faz de cada aula.

Professor: Sim, sim! [Feedback formativo realizado nov/2019]

Durante a formação, discutimos sobre o processo de avaliação. Esse diálogo serviu como diagnóstico para que eu pudesse perceber as concepções do docente a respeito do tema avaliação. 
Apesar de ter sido percebido que o professor não tem por hábito avaliar o processo de aprendizagem, e sim o produto final, após finalizar o conteúdo, não foi aproveitado o momento da conversa para possibilitar essa reflexão com o professor.

\section{Análise crítica da formação}

A partir dos dois momentos realizados neste estudo, o momento da observação das aulas e o da formação, é possível afirmar, de acordo com Almeida (2006), que os espaços na grade horária do professor coordenador e do professor para acontecer essas reuniões é fundamental e possibilitam reflexões sobre suas experiências em sala de aula e, por consequência, a formação em serviço. É necessário, no entanto, que essa formação esteja atrelada ao projeto político pedagógico da escola e que haja uma parceria de disponibilidade e de confiança entre os envolvidos.

Também é possível afirmar, a partir desses momentos do estudo, a importância da formação do PC como formador de professores, pois a falta de experiência prática e de discussões teóricas na sua formação não possibilitou que as discussões avançassem.

Das cinco teses destacadas por Nóvoa (2002) e já apresentadas neste artigo, sobre a formação em serviço, é possível afirmar que, a partir dos estudos realizados, apesar do PC ter observado questões relevantes para o processo do ensino e aprendizagem de matemática na EJA, não houve proposição na perspectiva de invocação que poderia ter contribuído com a formação do professor.

Em relação à valorização da (auto) formação defendida por este autor, é possível que as estratégias utilizadas pelo PC, de conversar sobre as observações com o professor, apesar de estarem pautadas em situações reais observadas, não acrescentaram reflexões-críticas que pudessem contribuir significativamente com a formação do professor.

Também é possível afirmar que o estudo realizado se baseou na tese defendida por Nóvoa (2002) "reflexão na prática e sobre prática", porém, não aconteceu a dinâmica de investigação e de ação na investigação.

Por fim, é possível afirmar que a principal contribuição da formação oferecida neste estudo foi para o próprio $\mathrm{PC}$, pois este teve sua primeira experiência de refletir sobre as possibilidades e dificuldades do oferecimento de uma formação em serviço. 


\section{Considerações}

O objetivo desta pesquisa foi compreender as possibilidades e desafios de realizar uma formação em serviço mediada pelo PC para um professor de matemática, concebida a partir das observações da sala de aula, guiadas pela ficha de observação, na perspectiva do PC.

Durante a elaboração da pauta formativa e no desenvolvimento da formação entre PC e professor, emergiram dois desafios importantes e que estão presentes na rotina de trabalho do PC. O primeiro é em relação ao tempo a ser dedicado à elaboração da pauta formativa, de forma que todas as observações feitas durantes as aulas sejam contempladas. E o segundo é em relação à falta de uma formação específica do PC em elaborar a pauta e em desenvolver formação com 0 professor.

Enfim, é possível afirmar que a formação em serviço tem potencial para contribuir com 0 processo ensino e aprendizagem, pois possibilita problematizar a prática real em sala de aula durante 0 processo formativo, porém, não é suficiente ter espaço, na grade horária dos profissionais envolvidos, professores e PC para observação e encontros, mas também se faz necessário que o PC tenha formação específica para se tornar um formador de professor.

\section{Referências}

ALMEIDA, L. R. de. A dimensão relacional no processo de formação docente: uma abordagem possível. In: BRUNO, E. B. G.; ALMEIDA, L. R.; CHRISTOV, L. H. S. (orgs). 0 coordenador pedagógico e a formação docente. São Paulo: Loyola, 2006.

ALMEIDA, L. R. de; PLACCO, V. M. N. de S. Coordenador pedagógico e questões da contemporaneidade (0). São Paulo: Edições Loyola, 2006.

ALMEIDA, L. R. de; PLACCO, V. M. N de S. O papel do coordenador pedagógico. Revista Educação, v. 12, n. 142, p. 7-11, 2009.

CANDAU, V. Formação continuada de professores: tendências atuais. In: REALE, A. M. M. R.; MIZUKAMI, M. G. N. (Orgs.). Formação continuada de professores: tendências atuais. São Carlos: Edufscar, 2003.

FONSECA, J. J. S. da. Metodologia da Pesquisa Científica. Fortaleza: UEC, 2002.

FREIRE, P. Política e Educação: Ensaios. 6. ed. São Paulo: Cortez, 2001.

GOUVEIA, B.; PLACCO, V. M. N. S. A formação permanente, o papel do coordenador pedagógico e a rede colaborativa. In: ALMEIDA, L. R.; PLACCO, V. M. N. S. O coordenador pedagógico e a formação centrada na escola. São Paulo: Edições Loyola, 2013. p. 69-80.

MARIN, A. J. Educação Continuada: introdução a uma análise de termos e concepções. São Paulo: Papirus, 1995.

NÓVOA, A. Formação de professores e trabalho pedagógico. Lisboa: Educa, 2002. 
OLIVEIRA, C. A. D. 0 papel do (a) professor (a) coordenador (a) pedagógico (a) na formação em serviço dos (as) docentes do ensino fundamental II: uma análise dessa função em uma rede municipal de ensino do interior paulista. 2018. 124 f. Dissertação (Mestrado em Educação) - Universidade Federal de São Carlos, São Carlos, SP, 2018.

PIMENTA, S. G.; GHEDIN, E. Professor Reflexivo no Brasil: gênese e crítica de um conceito. São Paulo: Cortez, 2002.

PLACCO, V. M. N. S. Formação e Prática do Orientador e do Educador. 5. ed. Campinas: Papirus, 2002.

SAMPAIO, M. M. O coordenador pedagógico e a formação continuada de professores em serviço: uma análise em escolas públicas da região metropolitana do estado de Sergipe. 2018. 156 f. Dissertação (Mestrado em Educação) - Universidade Federal de Sergipe, São Cristóvão, SE, 2018.

SILVA, P.S.; TRALDI, A. Jr. Linguagem matemática no processo de aprendizagem de um grupo de estudantes surdos. Revista da Sociedade Brasileira de Educação Matemática - Regional São Paulo, v. 16, n. 23, p. 323-347, 2019.

SILVEIRA, D. T. (Orgs.). Métodos de Pesquisa. Porto Alegre: Editora de UFRGS, 2009. p. 31 42.

SOUZA, L. R de. Formação continuada em serviço: do coordenador pedagógico ao professor: o caso da rede municipal de São Paulo. 2017. 106 f. Dissertação (Mestrado em Gestão e Práticas Educacionais) - Universidade Nove de Julho, São Paulo, 2017. 